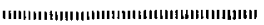

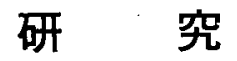

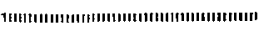

\title{
The Use of Radioactive Fission Product Rare Gases for the Study of the Phase \\ Change in Fine Particles
}

"Crystal Structure Change of $\gamma$-Hematite to $\alpha$-Hematite"

\begin{abstract}
Sumio Ichiba*
Hahn first investigated the emanation method which used radioactive radon nuclides as tracers.

In the present work, the use of radioactive fission product rare gas for the emanation method in place of radon was proposed. The crystal structure change of $\gamma$-hematite to $\alpha$-hematite was studied by this method and high temperature $\mathrm{X}$-ray diffraction method was employed for the identification of the crystal.

The usefullness of this emanation method for the studies in the field of physical chemistry is also discussed. (Received June 2,1961)
\end{abstract}

\section{Introduction}

Hahn first investigated the emanation method using radioactive radon nuclides ${ }^{2 * 2} \mathrm{Rn}\left(\mathrm{T}_{1 / 2}\right.$ $=3.83 \mathrm{~d}){ }^{230} \mathrm{Rn}\left(\mathrm{T}_{1 / 2}=54.5 \mathrm{sec}\right.$. $)$ and ${ }^{219} \mathrm{Rn}\left(\mathrm{T}_{1 / 2}=3.92 \mathrm{sec}\right.$. $)$ as tracers and pointed out the possible correlations beween the released radioactive radon atoms formed in a solid and the composition, crystal structure, specific surface and temperature of the solid. Since then, this method was applied to the studies of aging of precipitate, crystal structure change, decomposition reaction, reaction between fine particles and surface of the solids ${ }^{1)}$. In this method, radium, or thorium, a parent of radon nuclides, is usually incorporated into particles by coprecipitation with the solid or by deposition on the particles to be examined. But this method has not been used extensively, because of the samples cannot be prepared without chemical treatments and lack of the sensitivity of the radiation measuring instruments.

After the discovery of the nuclear fission phenomenon, the use of the radioactive krypton and xenon of the fission products was suggested ifor the emanation method. But no work which uses radioactive krypton and xenon for the emanation method has been done up to this date except for uranium ${ }^{2}$ and thorium ${ }^{82}$.

In the present work, the emantion method which uses the radioactive fission product rare gases in place of radon nuclides was applied to the study of the crystal structure change of

* Japan Atomic Energy Research Institute. 
Table 1 Nuclear Properties of Krypton and Xenon.

\begin{tabular}{|c|c|c|c|c|c|c|c|}
\hline \multirow{3}{*}{ Nuclide } & \multirow{3}{*}{$\begin{array}{c}\text { Mass } \\
\underset{A}{\text { Number }}\end{array}$} & \multirow{3}{*}{$\begin{array}{l}\text { Half -life } \\
\quad 1 / 2\end{array}$} & \multirow{3}{*}{$\begin{array}{c}\text { Yield,Y } \\
(96)\end{array}$} & \multicolumn{4}{|c|}{ Energy of Radiation } \\
\hline & & & & \multicolumn{2}{|c|}{ Beta Particles } & \multicolumn{2}{|c|}{ Gamma Transitions } \\
\hline & & & & $\begin{array}{c}\mathrm{E}_{\mathrm{b}} \\
(\mathrm{Mev})\end{array}$ & $(96)$ & $\begin{array}{c}\text { Eg } \\
(\mathrm{Mev})\end{array}$ & $(96)$ \\
\hline \multirow[t]{30}{*}{${ }_{36} \mathrm{Kr}$} & 82 & Stable & $3.5 \times 10^{-3}$ & 0 & 0 & 0 & 0 \\
\hline & $83 \mathrm{~m}$ & $114 \mathrm{~m}$ & 0.48 & 0 & 0 & 0.0322 & 100 \\
\hline & & & & & & 0.0093 & 100 \\
\hline & 83 & Stable & 0.48 & 0 & 0 & 0 & 0 \\
\hline & 84 & Stable & 1.1 & 0 & 0 & 0 & 0 \\
\hline & $85 \mathrm{~m}$ & $4.36 \mathrm{~h}$ & 1.5 & 0.835 & 80 & 0.305 & 20 \\
\hline & & & & & & 0.1495 & 80 \\
\hline & 85 & $10.27 y$ & 0.3 & 0.695 & 99 & 0 & 0 \\
\hline & 86 & Stable & 2.1 & 0 & 0 & 0 & 0 \\
\hline & 87 & $78 \mathrm{~m}$ & 2.7 & 1.27 & 25 & 2.3 & 25 \\
\hline & & & & 3.63 & 15 & 1.89 & 25 \\
\hline & & & & & & 0.41 & 25 \\
\hline & 88 & $2.77 \mathrm{~h}$ & 3.7 & 0.52 & 70 & 2.40 & 35 \\
\hline & & & $(0.8)$ & 0.9 & 10 & 2.19 & 18 \\
\hline & & & & 2.7 & 20 & 1.85 & 15 \\
\hline & & & & & & 1.55 & 14 \\
\hline & & & & & & 1.20 & 4 \\
\hline & & & & & & 0.85 & 23 \\
\hline & & & & & & $0.365^{\circ}$ & 5 \\
\hline & & & & & & 0.191 & 35 \\
\hline & & & & & & 0.163 & 1 \\
\hline & & & & & & 0.028 & 1 \\
\hline & 89 & $3.18 \mathrm{~m}$ & $(4.6)$ & 4.0 & 100 & 0 & 0 \\
\hline & 90 & $\sim 33 \mathrm{~s}$ & $(5.2)$ & 3.2 & 100 & 0 & 0 \\
\hline & 91 & $9.8 \mathrm{~s}$ & $(3.7)$ & 3.6 & 100 & 0 & 0 \\
\hline & 92 & $3.0 \mathrm{~s}$ & $(2.7)$ & 5.0 & 100 & & $\sim 0$ \\
\hline & 93 & $2.0 \mathrm{~s}$ & $(1.3)$ & 8.0 & 100 & & $\sim 0$ \\
\hline & 94 & $1.4 \mathrm{~s}$ & $(0.6)$ & 6.4 & 100 & & $\sim 0$ \\
\hline & 95 & Short & $(0.2)$ & 9.3 & 100 & & $\sim 0$ \\
\hline & 97 & $1 \mathrm{~s}$ & $(\sim 0)$ & 10.6 & 100 & & $\sim 0$ \\
\hline \multirow[t]{22}{*}{${ }_{54} \mathrm{Xe}$} & 129 & Stable & $\begin{array}{c}1.0 \\
4 \times 10^{-4}\end{array}$ & 0 & 0 & 0 & 0 \\
\hline & $131 \mathrm{~m}_{2}$ & $12.0 \mathrm{~d}$ & 0.03 & 0 & 0 & 0.163 & 100 \\
\hline & 131 & Stable & 2.9 & 0 & 0 & 0 & 0 \\
\hline & 132 & Stable & 4.4 & 0 & 0 & 0 & 0 \\
\hline & $133 \mathrm{~m}$ & $2.3 \mathrm{~d}$ & 0.16 & 0 & 0 & 0.233 & 100 \\
\hline & 133 & $5.270 \mathrm{~d}$ & 6.5 & 0.345 & 100 & 0.081 & 100 \\
\hline & 134 & Stable & 7.6 & 0 & 0 & 0 & 0 \\
\hline & $135 \mathrm{~m}$ & $15.6 \mathrm{~m}$ & 1.8 & 0 & 0 & 0.52 & 100 \\
\hline & 135 & $9.13 \mathrm{~h}$ & 6.2 & 0.548 & 5 & 0.60 & 4 \\
\hline & & & 0.3 & 0.910 & 95 & 0.37 & 1 \\
\hline & & & & & & 0.250 & 96 \\
\hline & 136 & Stable & 6.3 & 0 & 0 & 0 & 0 \\
\hline & & & 3.2 & & & & \\
\hline & 137 & $3.9 \mathrm{~m}$ & $(5.9)$ & 4.0 & 100 & 0 & 0 \\
\hline & & & $(1.3)$ & & & & \\
\hline & 138 & $17 \mathrm{~m}$ & (5.5) & 3.07 & 100 & & $\sim 0$ \\
\hline & & & $(2.1)$ & & & & \\
\hline & 139 & $41 \mathrm{~s}$ & $(4.7)$ & 5.15 & 100 & & $\sim 0$ \\
\hline & 140 & $16 \mathrm{~s}$ & $\begin{array}{l}(2.9) \\
(3.7)\end{array}$ & 3.97 & 100 & & $\sim 0$ \\
\hline & 141 & $1.7 \mathrm{~s}$ & $(1.8)$ & 6.07 & 100 & & $\sim 0$ \\
\hline & 143 & Is & $(0.2)$ & 6.95 & 100 & & $\sim 0$ \\
\hline & 144 & 1s & $(\sim 0)$ & 5.78 & 100 & & $\sim 0$ \\
\hline
\end{tabular}


$\gamma$-hematite to $\alpha$-hematite.

\section{ll The Usable Nuclides in Fission Product Rare Gases for the Emanation Method}

A major fraction of uranium-235 thermal fission products consists of gaseous materials and the sum of independent and primary cumulative yields of all gaseous fission products, including iodine, bromine, xenon, krypton, amount to $52.3 \%$. Of this value $55.3 \%$, or a yield of $28.9 \%$, is attributed to xenon and krypton. The nuclear properties of the fission product xenon and krypton are listed in Table 1. The usable nuclides for the emanation method were selected by considering follwing conditons:

1) A nuclide of which half-life is long enough to enable an emanation experiment.

2) A nuclide which has a large activity.

3) A nuclide of which radioacitivity is not interfered with the precursor and the radioactivity of the other nuclides.

In Table 1, the krypton-85m, xenon-135 and xenon-133 have considerably long half-lives and large fission yields. To investigate the interference of the precursor and the radioactivity of the other nuclides, the changes of the radioactivity of the krypton $-85 \mathrm{~m}$, xenon-135 and xenon-133 after irradiation with time are measured and these changes are plotted in Fig.1. In these experiments, a polyethylene sheet containing $20 \mathrm{mg}$. of uranium dioxide is irradiated by the thermal neutron flux, $-5 \times 10^{11} \mathrm{n} / \mathrm{cm}^{2}$. sec. for two hours. The sample is placed in a small flask after each cooling period and the sheet is broken, and the uranium dioxide is dissolved in concentrated nitric acid. The helium gas is flowed through the flask, a trap cooled by dry ice (for iodine), charcoal trap cooled by freezing mixture of ice and sodium chloride (for xenon) and charcoal trap cooled by liquid nitrogen (for krypton) during treatments and for ten minutes after the uranium has been dissolved. The radioactivities of the krypton and xenon trapped in charcoal are measured by multi-channel-gamma ray spectrometer. The gamma-ray spectra of them are shown in Fig. 2. The cooling periods to minimize the interference of precursor and radioactivity of the other nuclides are found to be 1.5 and 4 days for xenon-135 and xenon-133, respectively. The use of one of these nuclides depends on the nature of the sample and the function of the measuring instrument and the cooling period is therefore determined by the nuclide thus selected.

\section{Incorporation of Rare Gases of Fission Product into a Solid}

When a mixture of uranium dioxide (fine powder) and solid powder of which weight ratio

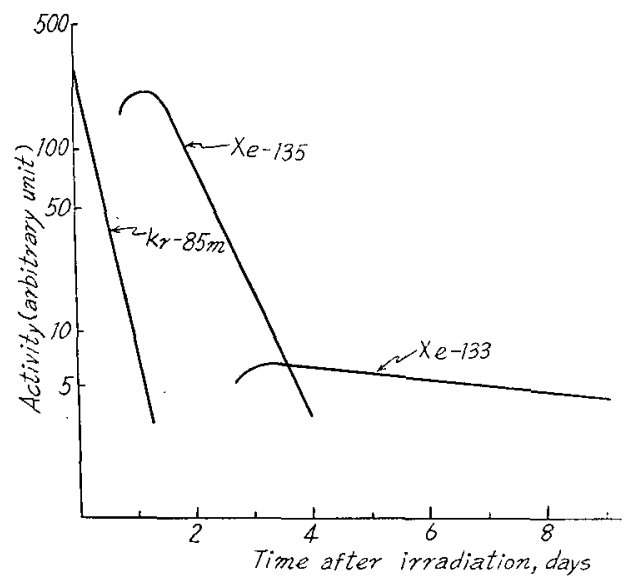

Fig. 1 Change of the radioactivities of the fission product krypton and xenon with time after two hour irradiation.

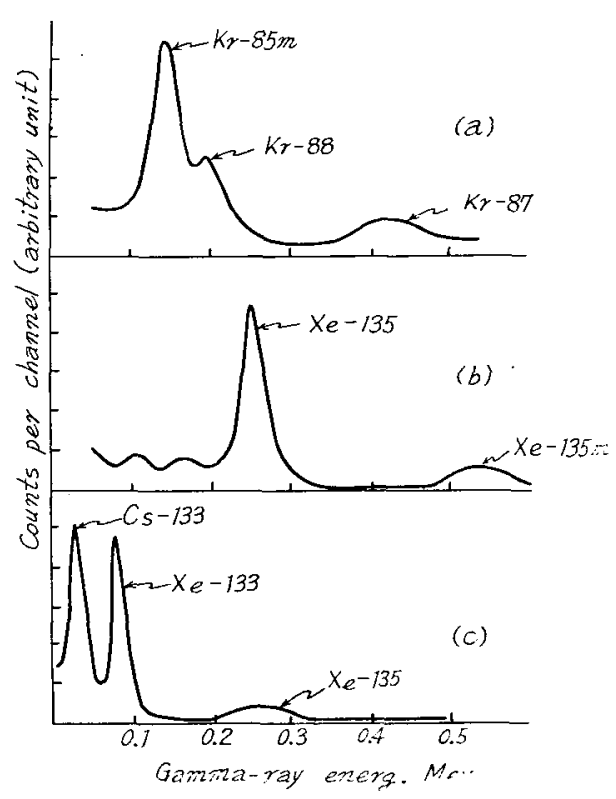

Fig. 2 Gamma-ray spectra of the fission product rare gases.

(a) $2 \mathrm{hr}$. irradiation and $8 \mathrm{hr}$. cooling.

(b) 2hr. irradiation and 1.5day cooling.

(c) $2 \mathrm{hr}$. irradiation and 5day cooling. 
of uranium dioxide to solid is less than $1: 10$, is irradiated by a thermal neutron flux, the most fission fragments will be captured in the surrounding solid powder ${ }^{4,5,6)}$. In our experiments, the uranium dioxide must be removed after irradiation, because the solid and uranium dioxide will react at high temperature and the resulting heating curves will be affected. Instead of uranium dioxide powder the thin formvar film containing uranium dioxide powder (particle size $\sim 0.2 \mu$ ) in a small size, is mixed with a solid powder to be examined and the mixture is irradiated by the thermal neutrons. The fission recoil energy enables the fission products to be caught by the surrounding solid powder through the film. After cooling period, the liquid which does not solve the samples (water, alcohol, carbon tetrachloride etc:) is added and the formvar film is sepatated by pouring on a wire-gauze. Then the solid powder containing fission products is obtained by filtering the liquid with the filter paper.

\section{Experimental}

In the emanation method, the samples containing radioacitive rare gases were heated at constant heating rate and the activity of the escaping rare gases were measured (heating curves), or the samples were heated at a various temperature and kept at these temperature while the changes in escaped radioactivity with time were followed (isothermal curves).

In the present work, the crystal structure change of $\gamma$-hematite to $\alpha$-hematite is studied by the heating curve: An X-ray diffraction method is also employed to identify the crystal structures. The hematites to be examined are shown in Table 2. The electron-microscopic photographs of each powder are also shown in Fig. 3.

Table 2. The hematite samples and their preparation method.

\begin{tabular}{c|c|l}
\hline Sample No. & Chemical form & \multicolumn{1}{c}{ Preparation method } \\
\hline 1 & $\boldsymbol{\alpha}-\mathrm{Fe}_{2} \mathrm{O}_{3}$ & dehydration of $\boldsymbol{\alpha}-\mathrm{FeO} \cdot \mathrm{OH}$ at $250^{\circ} \mathrm{C}$ \\
2 & $\boldsymbol{\alpha}-\mathrm{Fe}_{2} \mathrm{O}_{b}$ & dehydration of $\boldsymbol{\alpha}-\mathrm{FeO} \cdot \mathrm{OH}$ at $300^{\circ} \mathrm{C}$ \\
3 & $\boldsymbol{\alpha}-\mathrm{Fe}_{2} \mathrm{O}_{3}$ & thermal decomposition of $\mathrm{FeSO}_{4} \cdot 7 \mathrm{H}_{2} \mathrm{O}$ at $780^{\circ} \mathrm{C}$ \\
4 & $\gamma-\mathrm{Fe}_{2} \mathrm{O}_{3}$ & oxidation of $\mathrm{Fe}_{3} \mathrm{O}_{4}$ at $250^{\circ} \mathrm{C}$ \\
5 & $\gamma-\mathrm{Fe}_{2} \mathrm{O}_{3}$ & pure $\boldsymbol{\gamma}-\mathrm{Fe}_{2} \mathrm{O}_{3}$ \\
\hline
\end{tabular}

The fission product rare gases are incorporated into the hematite samples as described above. That is, $200 \mathrm{mg}$. of thin film of formvar, containing uranium dioxide whose weight ratio to formvar is $1: 5$ was mixed with $500 \mathrm{mg}$. of hematite and irradiated by thermal neutron flux $\sim 5 \times 10^{11} \mathrm{n} / \mathrm{cm}^{2}$. sec. for 2 hours in an experimental hole of JRR-1 reactor. After 1.5 day cooling period, alcohol was added to the sample and the solid powder retaining fission products was separated by a wire gauze and then was dried. Then, the solid powder was placed in a quartz tube which was connected with a phosphorus pentaoxide drying tube, a dry ice trap for radioacive iodine, a counting cell inserted into a NaI scintillation crystal well of $\gamma$-ray spectrometer and a flow rate meter, in the order mentioned. The schematic diagram of the apparatus is shown in Fig. 4. Pure argon gas was passed over the solid powder at a flow rate of $100 \mathrm{ml} / \mathrm{min}$., and solid powder was heated by a furnace surrounding the quartz tube at a rate of $5^{\circ} \mathrm{C} / \mathrm{min}$. The radioactive xenon- 135 escaping from hematite was carried in argon and the radioactivity was measured by the scintillation crystal. The plots of the radioactivity of xenon-135 escaped from hematites versus temperature are shown in Figs. 5 9.

The correlations between the observed peaks in the heating curves and the crystal structre 


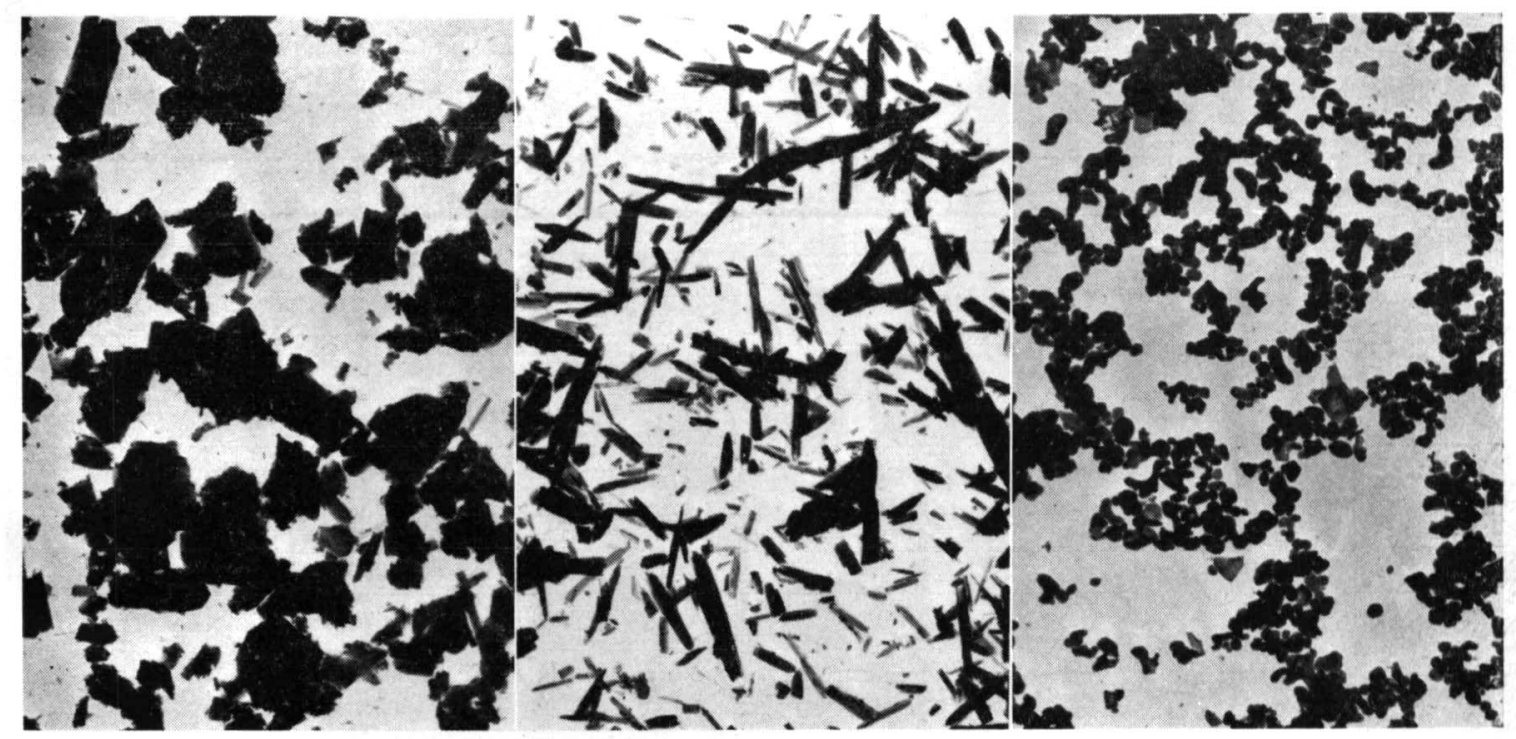

(a) $\boldsymbol{\alpha}$-hematite (No.1)

(b) $\boldsymbol{\alpha}$-hematite (No.2)

(c) $\boldsymbol{\alpha}$-hematite (No.3)

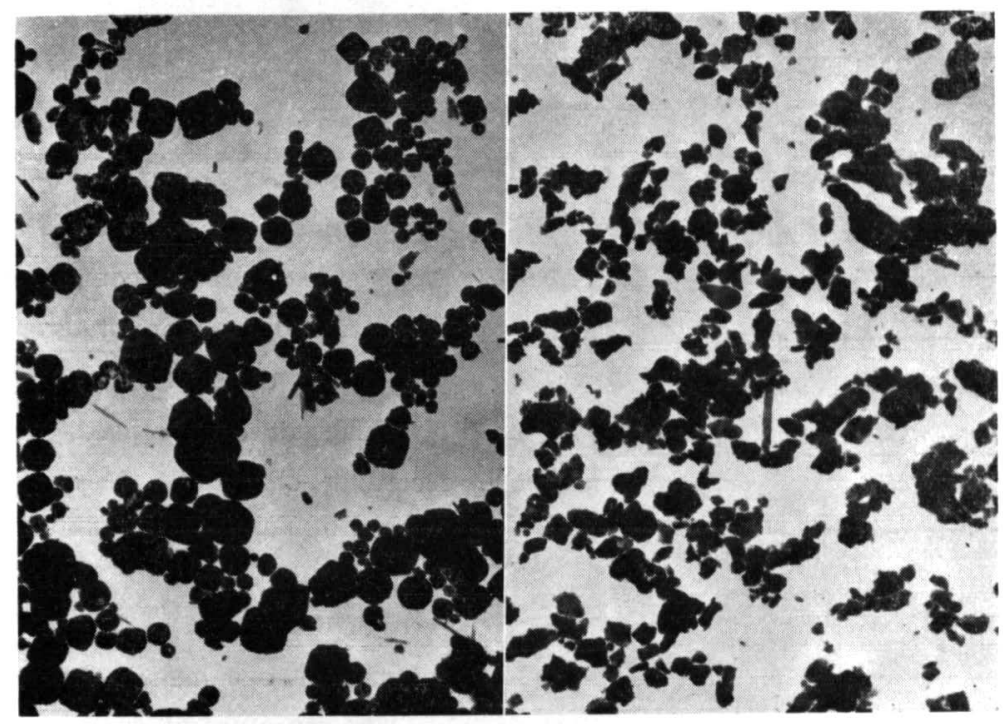

(d) $\gamma$-hematite (No.4)

(e) $\gamma$-hematite (No.5)

Fig. 3 Electron microscopic photographs of hematite sample. $(\times 10,000)$

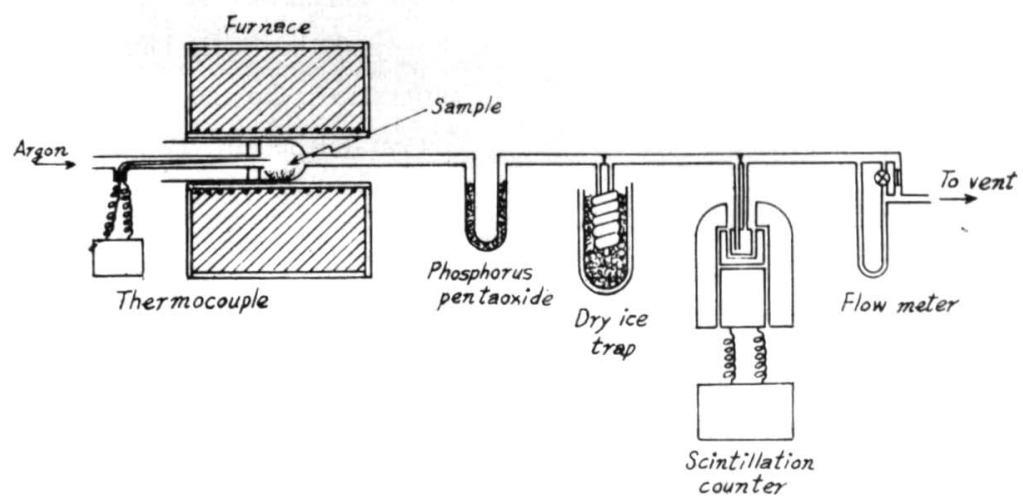

Fig. 4 Schematic diagram of the heating apparatus. 


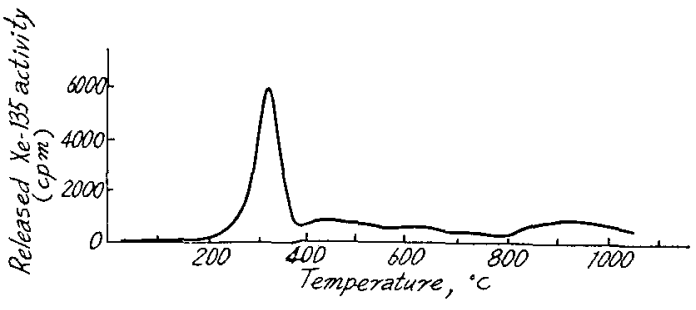

Fig. 5 Heatig curve $\left(5^{\circ} \mathrm{C} / \mathrm{min}\right.$.) of $\alpha$-hematite sample (No.1).

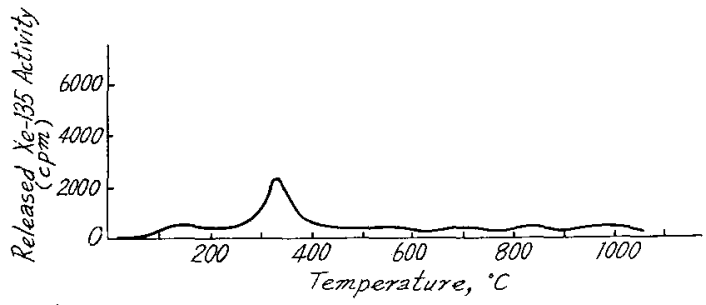

Fig. 6 Heating curve $\left(5^{\circ} \mathrm{C} / \mathrm{min}\right.$.) of $\boldsymbol{\alpha}$-hematite sample (No.2).

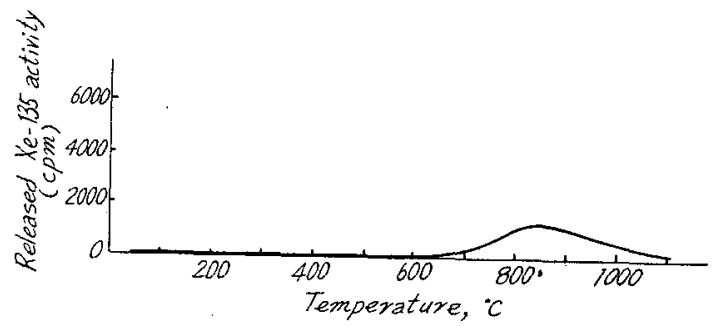

Fig. 7 Heating curve $\left(5^{\circ} \mathrm{C} / \mathrm{min}\right)$ of $\boldsymbol{\alpha}$-hematite sample (No.3).

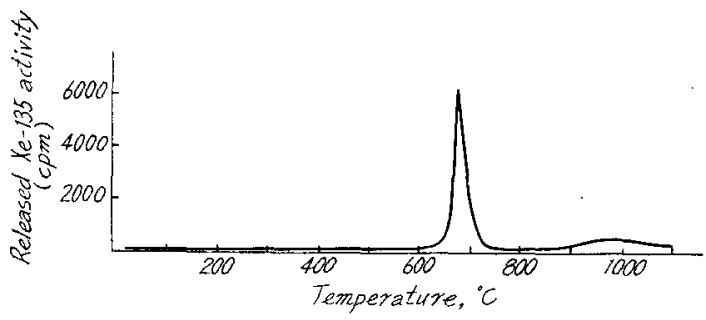

Fig. 8 Heating curve $\left(5^{\circ} \mathrm{C} / \mathrm{min}\right.$.) of $\gamma$-hematite sample (No.4).

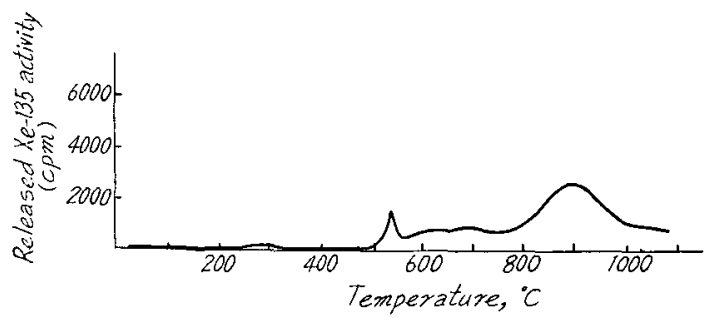

Fig. 9 Heating curve $\left(5^{\circ} \mathrm{C} / \mathrm{min}\right.$. $)$ of $\gamma$-hematite sample (No.5). changes were studied by an X-ray diffraction method at temperatures below and over the temperatures where the peaks appear. The $\gamma$-hematite samples (Nos. 4 and 5) were also investigated by the continuous recording method by the use of the peaks (220) of $\gamma$-hematite and (104) of $\alpha$-hematite. The charts are shown in Figs. 10 and 11.

\section{Results and Consideration}

The peaks in the heating curves of Figs. 5 and 6 are considered to be related to the dehydration of $\mathrm{FeO} \cdot \mathrm{OH}$, although the $\mathrm{X}$-ray diffraction diagram shows that the No.2 sample is $\alpha$-hematite at room temperature.

In Fig. 7, the sharp peak is not observed because no change in structure takes place. The slow ascendant of the curve probably shows that the xenon trapped in the imperfection of the crystal are released. The samples of Nos. 4 and 5 are identified to be $\gamma$-hematite at room temperature by an $\mathrm{X}$-ray diffraction study, but the heating curves of Figs. 8 and 9 are considera. bly different each other. The continuous recording charts using $\mathrm{X}$-ray diffraction method of Figs. 10 and 11 show that the peaks at $680^{\circ} \mathrm{C}$ and $530^{\circ} \mathrm{C}$ are the temperatures of the crystal structure change from $\gamma$-hematite to $\alpha$-hematite respectively.

The structure of $\gamma$-hematite is spinel type in which the layers of close-packed oxide ion have a stacking of $A, B, C, A, B, C$, ...... and the ferric ions are present in its interstices. On the other hand, $\alpha$-hematite as established by Pauling and Henedricks, has a Rhombohedral structure in which close-packed oxide ion layers have a st. acking of $A, B, A, B, \cdots \cdots$.

Crystallographic orientation relationship between $\gamma$ and its transformed phase $\alpha$ was made clear by the electron diffraction study of Kachi and Momiyama ${ }^{7}$ in their coexistent state as follows. 


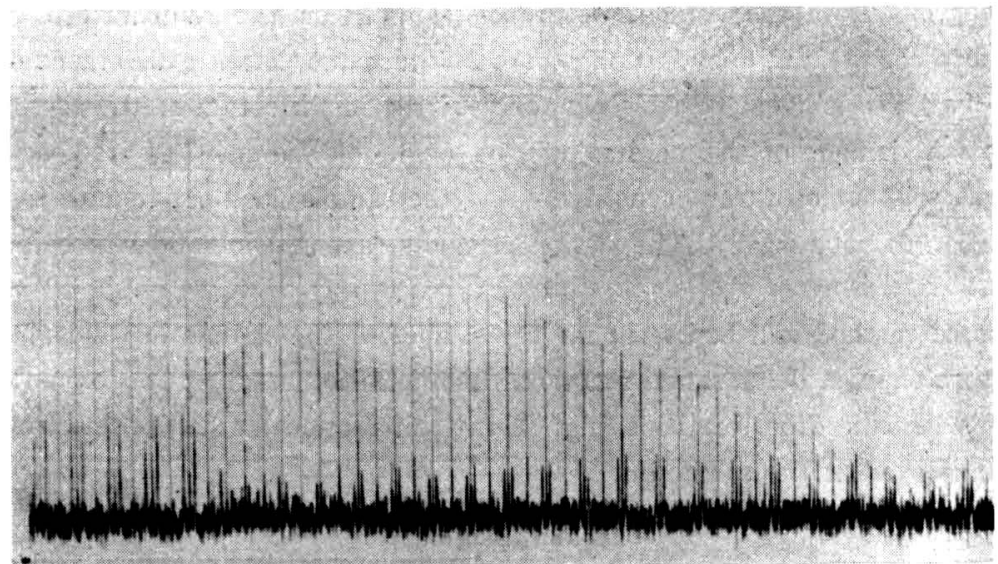

Fig. 10 Continuous recording chart of high temperature X-ray diffraction of No.4 $\boldsymbol{\gamma}$-hematite sample. Successive vertical lines indicate temperature.

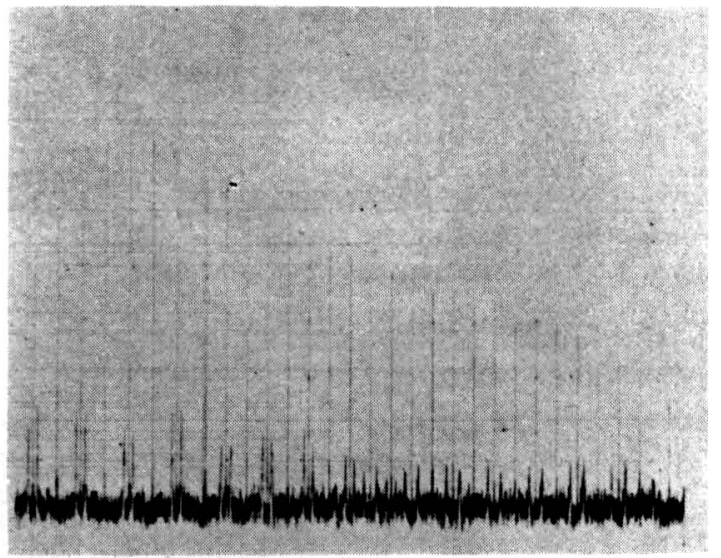

Fig. 11 Continuous recordig chart of high temperature X-ray diffration of No.5 $\boldsymbol{\gamma}$-hematite sample. Successive vertical lines indicate temperature.

(110) $\gamma / /(11 \overline{2}) \alpha$ (Rhombohedral)

(113) $\gamma / /$ (101) $\alpha$ (Rhombohedral)

Based on this relation the following transition mechanism was proposed by Kachi ${ }^{\text {l) }}$ et al.

1. The stacking of $A, B, C, A, B, C, \cdots \cdots$ of oxide ion layer in $\gamma$-hematite changes to $A, B$, $A, B, \cdots .$. type by the movement of half dislocation in alternate oxide ion layers (in the same mechanism as the transition of metalic Co from f.c c. to h.c.p.).

2. Synchronously with the above movement, ferric ions which present in interstices of oxide ions change from spinel to rhombohedral configuration by the short range diffusion so as to satisfy the electrostatic equilibrium.

Therefore, the prompt release of $\mathrm{Xe}$ at the transition temperature in Fig. 8 and 9 shows that the Xe atoms trapped by the imperfection such as dislocation or point defect in $\gamma-\mathrm{Fe}_{2} \mathrm{O}_{8}$ are swept out of the crystal by the movement of dislocation, because the innert Xe atom has no chemical interaction with surrounding atoms.

In Fig. 8 and 9 the peak above the transition temperature (in $\alpha$-hematite region) have a same position as the peak found in $\alpha$-hematite obtained from $\alpha-\mathrm{FeOOH}$.

This may show that the imperfections which trap $\mathrm{Xe}$ in $\alpha$-hematite are same sorts, in spite of its different origin. 
The heating curves of the emanation method can tell us the temperature at which the crystal structure change and dehydration occurs and also the detailed difference of the crystal structure. It may also suggest possible existence of the imperfection of the crystal.

The radiation damage of the crystal will be negligible because the radioactivity of the fission rare gases is detected very sensitively and the sample does not require so much irradiation as radiation damage occurs. The fission products captured in solid will be also negligible as impurities.

The proposed method will be useful for the studies of the change in solid phase, such as, crystal structure change, dehydration reaction, decomposition reaction and oxidation and reduction reaction when the other methods, e.g., X-ray diffraction method or electron diffraction method, are employed at the same time.

\section{Acknowledgment}

The author wishes to thank Prof. S. Kachi of Kyoto University for invaluable suggestions to this work and also for providing the hematite samples.

\section{References}

1) A. C. Wahl and N.A. Bonner, "Radioactivity Applied to Chemistry", John Wiley \& Sons, Inc., New York, (1951), p. 284

2) O. Hahn and F. Strassemann, Naturwissenschaften 28 (1940), 61

3) H. Goette and G. Radock, Z. Naturforsch. 2a (1947), 427

4) R. Wolfgang, J. Inorg. and Nucl. Chem. 2 (1956), 180

5) R. Henry and C. Herczeg, UNESCO/NS/RIC/14 (1957)

6) T. Nakai and S. Yajima, J. Chem. Soc. Japan, Pure Chem. Sec., (Nippon Kagaku Zassi), 79 (1958), 1267

7) To be published in this Journal.

\section{Planseeberichte Bd. 9 \\ Nr. 1/2 April 1961}

1. Über die Einwirkung von chemisch nicht reagierenden Gasen auf technische Prozesse und auf Mineralbildung

2. Die pulvermetallurgie als Didaktikum

3. Theory and Application in the History of Powder Metallurgy

4. Continuous Production of High Strength Lead Strip by Direct Powder Rolling

5. Sintering Behavior of Loose Metal Powders

6. Swelling of an Iron Copper Compact During Sintering

7. Refractory Coatings for Tungsten

8. Ein Beitrag zum Oberflächenschutz von Molybdän bei hohen Temperaturen

9. Oxidation protection of Columbium Alloys Through Coating by Pack Diffusion Technique

10. Die Ultraschallprüfung von Sinterstäben hochschmelzender

11. Zur Bestimmung des Vanadiums in WoIfram-Vanadium-Legierungen

12. Die thermische Ausdehnung hochschmelzender Phasen

13. A Note on Vacuum Sintered Fine-Particle Titanium Carbide

14. Zur Kentnis der Systeme Uran-Zirkonium(Hafnium, Niob, Tantal) Kohlenstoff

15. A New Test for Determining Resistance to Thermal Shock of $\mathrm{TiB}_{2}$ Base Compositions

16. Alloys of Tantalum Diboride with Iron, Cabalt and Nickel

17. Electrode Potential and Corrosion Behavior of Some Borides of Molybdenum and Zirconium

18. The Boron Carbide Structure Type

19. Some Aspects of Disperion Hardening in the Uranium-Uranium Oxide System

20. Survey of Literature 